\section{Human dignity must be basis for debate on primate research}

SIR - Bill Crum emphasizes

a fundamental keynote of biomedical-research ethics in his Correspondence 'It should be possible to replace animals in research' (Nature 457, 657; 2009) by stating that "good medical science" is not necessarily "morally justifiable or morally acceptable". On the other hand, many states and societies claim 'freedom of research' - meaning research being free from the need for justification - as a basic right. On the face of it, this looks like a discrepancy.

However, we have to recognize the fact that this freedom, like every other kind of freedom, has its ethical limits. Research can only be a right as long as it is not acting against our fundamental moral value: respect for human dignity. This is the basic point that we should agree on, regardless of our different opinions on what might constitute a breach of that principle.

With human dignity in mind, the ethical discussion about research on non-human primates has to focus on answering two questions. First, would prohibiting studies on primates constitute a threat to the human dignity of future generations, by reducing their chances of what we could consider a good life, as Roberto Caminiti states in his Correspondence 'Replacement of animals in research will never be possible' (Nature 457, 147; 2009)? Second, is performing "invasive medical experiments" on creatures that "provide excellent experimental models of human cognition", as Crum states, a threat to our own dignity and our vision of how a good life should be led?

Only by using human dignity as the normative correlate for ethical decisions can we ensure that these decisions will be made on a basis that is equally important to all parties in this debate. Tim Fieblinger Basal Ganglia Pathophysiology Unit, Lund University, BMC F11-46, 22184 Lund, Sweden e-mail: tim.fieblinger@med.lu.se

Readers are welcome to comment at http://tinyurl.com/c62pgf

\section{Rare BSE mutation raises concerns over risks to public health}
SIR - Atypical forms (known as $\mathrm{H}$ - and L-type) of bovine spongiform encephalopathy (BSE) have recently appeared in several European countries as well as in Japan, Canada and the United States. This raises the unwelcome possibility that variant Creutzfeldt-Jakob disease (vCJD) could increase in the future outbreaks.
Malcolm A. Ferguson-Smith Cambridge University Department of Veterinary Medicine, Madingley Road, Cambridge CB3 OES, UK e-mail:maf12@cam.ac.uk Jürgen A. Richt College of Veterinary Medicine, Kansas State University, K224B Mosier Hall, Manhattan, Kansas 66506-5601, USA human population.

Of the atypical BSE cases tested so far, a mutation in the prion protein gene (PRNP) has been detected in just one, a cow in Alabama with BSE; her healthy calf also carried the mutation (J. A. Richt and S. M. Hall PLoS Pathog. 4, e1000156; 2008). This raises the possibility that the disease could occasionally be genetic in origin. Indeed, the report of the UK BSE Inquiry in 2000 suggested that the UK epidemic had most likely originated from such a mutation and argued against the scrapierelated assumption.

Such rare potential pathogenic PRNP mutations could occur in countries at present considered to be free of BSE, such as Australia and New Zealand. So it is important to maintain strict surveillance for BSE in cattle, with rigorous enforcement of the ruminant feed ban (many countries still feed ruminant proteins to pigs). Removal of specified risk material, such as brain and spinal cord, from cattle at slaughter prevents infected material from entering the human food chain.

Routine genetic screening of cattle for PRNP mutations, which is now available, could provide additional data on the risk to the public. Because the point mutation identified in the Alabama animals is identical to that responsible for the commonest type of familial (genetic) CJD in humans, it is possible that the resulting infective prion protein might cross the bovine-human species barrier more easily. Patients with vCJD continue to be identified. The fact that this is happening less often should not lead to relaxation of the controls necessary to prevent

\section{Scientific links with Cuba flourished despite US embargo}

SIR - In your Editorial 'Cuba's biotech boom' (Nature 457, 130; 2009), you state that "despite many constraints on interaction between Cuban and US scientists, biotech has prospered". In fact, US biotechnologists contributed in no small way to its development.

At the start, during the early 1980s, Cuban biotechnology was confined to a small house in a Havana suburb. An American group organized by Harlyn Halvorson, then director of Brandeis University's Rosenstiel Center and an inspirational leader, stepped in to help the venture. We were received warmly in Cuba whenever we visited.

The biotechnology effort soon transferred to a larger house across the street and from 1986 was housed in the majestic Center for Genetic Engineering and Biotechnology. The Cuban scientists set up symposia where one or more of us would speak.

The US government allowed us to travel to Cuba on the condition that we spent no American dollars there. We therefore continued to advise this fledgling group until the Soviet Union ceased to support Cuba financially and they could no longer pay for our visits. Arnold L. Demain Research Institute for Scientists Emeriti, Drew University, Madison, New Jersey 07940, USA e-mail: ademain@drew.edu

\section{Idea of a love drug was no mystery to Shakespeare}

SIR — In his Essay 'Love: neuroscience reveals all' (Nature 457, 148; 2009), Larry Young claims that the biochemical understanding of love is not poetry. But at least one poet, namely William Shakespeare, foretold the application of drugs to manipulate the brain systems associated with pair bonding.

In A Midsummer Night's Dream, Oberon maintains that topical applications of the juice of the wild pansy (Viola tricolor, called 'love-in-idleness' in the play) "Will make or man or woman madly dote Upon the next live creature that it sees" (Act 2, Scene 1). The potion proves highly effective, supplying much of the humour in the play as Titania falls in love with the donkey-headed Bottom. Shakespeare also suggests that other substances from "Dian's bud" - variously identified as a species of wormwood (Artemisia spp.) or chaste tree (Vitex agnuscastus, a species not native to England but long known for its anti-libidinal properties) - could reverse the neurobiological results of the pansy. Perhaps poets have something to teach us about neurobiology and love after all.

Joan G. Ehrenfeld Department of Ecology, Evolution and Natural Resources, SEBS, 14 College Farm Road, New Brunswick, New Jersey 08901, USA e-mail: ehrenfel@rci.rutgers.edu

Contributions may be submitted tocorrespondence@nature.com. 